\title{
Septicaemia and adrenal haemorrhage in congenital asplenia
}

\author{
M P Dyke, R P Martin, P J Berry
}

\begin{abstract}
Five patients developed overwhelming infection as a result of congenital asplenia, which was previously unsuspected in all cases. Each illness followed a fulminant course resulting in death within 24 hours. They illustrate the respective roles of Haemophilus influenzae infection $(n=4)$ and adrenal haemorrhage $(n=4)$ in this condition. We suggest a management protocol for screening infants with abnormalities of the atria or viscera with splenic ultrasound and examination of a blood film for Howell-Jolly bodies. Vaccination and prophylactic antibiotics should be considered for those at risk. Vigorous use of parenteral antibiotics and steroids in suspected infection is recommended.
\end{abstract}

Congenital asplenia, or polysplenia, may occur in isolation, or as one of several abnormalities of the heart and viscera. ${ }^{1-5}$ Two main groups of abnormality have been described. Asplenia may be associated with right isomerism, which presents as bilateral trilobed lung and situs inversus of abdominal organs. Polysplenia may occur with left isomerism, bilateral bilobation of the lung, and abdominal heterotaxy. ${ }^{5-7}$

Over $90 \%$ of cases are associated with complex congenital heart disease, ${ }^{5}$ and the high mortality rate in the early months of life has been largely attributable to this. ${ }^{58}$ As surgical techniques and supportive care improve, however, many more children with severe heart disease can be expected to survive the first few months. ${ }^{9}$ Waldman et al found that infants with asplenia who survived the first month were more likely to die from sepsis than from their heart disease. ${ }^{8}$ Several reports have described sepsis in asplenic patients and a number of consistent features emerge. ${ }^{8} 10-15$ Infecting organisms are usually pneumococcus or Haemophilus influenzae. The course of the illness is commonly fulminant with the rapid onset of hypovolaemic shock, disseminated intravascular coagulopathy, and loss of consciousness. Mortality is extremely high, being at least $50 \%$ in all series and greater than $80 \%$ in many. It is, therefore, becoming increasingly important to seek out evidence of anatomical or functional hyposplenia and to institute measures to protect those infants at risk from overwhelming infection.

We describe five patients who presented to the Bristol Children's Hospital between 1982 and 1990 in whom hyposplenism was not previously suspected and whose illnesses were fulminant and ultimately fatal.

\section{Case reports}

CASE 1

A previously well 2 year old boy presented with 24 hours of fever followed by diarrhoea and rigors. Rectal temperature was $40^{\circ} \mathrm{C}$ and he was centrally cyanosed with tachypnoea, tachycardia, and unrecordable blood pressure. Despite being given antibiotics, plasma, and methyl prednisolone he died eight hours after admission.

Necropsy showed no abnormality except for an extremely small spleen ( $10 \mathrm{~g}$ ) and bilateral adrenal haemorrhage. $H$ influenzae type $\mathrm{B}$ was cultured from the blood.

\section{CASE 2}

A baby girl who was known to have right atrial isomerism, double inlet and double outlet indeterminate ventricle, a complete atrioventricular septal defect with common atrioventricular valve, and pulmonary stenosis presented at 3 months of age with a simple upper respiratory infection that lasted for $\mathbf{1 0}$ days and culminated in acute cardiovascular collapse. She died from cardiac and renal failure within 24 hours of admission to hospital despite full support including peritoneal dialysis.

Necropsy confirmed the cardiac abnormalities and showed that she had no spleen, her stomach and pancreas were on the right, and she had a narrow midline mesenteric root. She also had bilateral adrenal haemorrhages and $H$ influenzae type $\mathrm{B}$ was subsequently cultured from her blood.

\section{CASE 3}

A 15 month old child presented with a few hours' history of vomiting and fever, followed by loss of consciousness and a single generalised convulsion. There was no localised infection but dextrocardia was noted. Antibiotics and full supportive treatment were started, but the child had a cardiac arrest and resuscitation was unsuccessful. $H$ influenzae type B was cultured from blood and cerebrospinal fluid.

Necropsy showed thoracic and abdominal situs inversus. There were small splenunculi in the right upper quadrant of the abdomen and both adrenal glands were haemorrhagic.

\section{CASE 4}

A baby girl was found to have dextrocardia with right atrial isomerism, ambiguous atrioventricular connection, complete atrioventricular septal defect with common atrioventricular valve, double outlet right ventricle, pulmonary valve

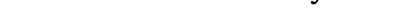

\author{
P J Berry \\ Correspondence to: \\ Dr Dyke. \\ Accepted 14 January 1991 \\ Sick Children, \\ St Michael's Hill
Bristol BS2 8BJ \\ Institute of Child Health \\ M P Dyke \\ Department of Pathology
}


stenosis, and bilateral superior vena cavas at birth. She remained well until 9 months of age when she presented with laboured respiration and cyanosis of sudden onset. Initial investigations showed no abnormalities except for a chest radiograph, which showed free gas under the diaphragm. She was treated with artificial ventilation, plasma, and antibiotics, but died shortly after admission.

Necropsy confirmed the cardiac abnormalities. Abdominal viscera were normal although the small bowel mesentery was narrow. There was necrotising gastritis with free peritoneal gas and fluid from which Pseudomonas aeruginosa was isolated. She had no spleen.

CASE 5

A previously fit 7 month old boy presented with a two hour history of fever and listlessness. Initial examination showed that he had a temperature of $37.6^{\circ} \mathrm{C}$ and respirations of $60 /$ minute. Four hours later he collapsed; his skin became grey and mottled, and he developed tachycardia with increasing tachypnoea. Investigations showed no abnormality except for a relative neutropenia. He died six hours later despite treatment with artificial ventilation, inotropic agents, plasma, steroids, and antibiotics.

Necropsy showed a normal thoracic cavity but the liver and gall bladder were in the midline, and he had an annular pancreas and a narrow mesenteric root. Both adrenal glands were haemorrhagic and there was no spleen. $H$ influenzae type $\mathrm{B}$ was subsequently cultured from the blood.

\section{Discussion}

Although the increased risk of bacterial infection in the asplenic host is well known, congenital asplenia is still largely unrecognised as a cause of sudden unexpected death in infancy. ${ }^{8}$ 10-15 Our series illustrates several important features of the problem. Firstly, there is an association with cardiac and other abnormalities. Two of our cases had complex lesions similar to those previously described, ${ }^{1-7}$ and a third had dextrocardia. Viscera were abnormally placed in three. Secondly, $H$ influenzae is an important pathogen, and was isolated from blood in four cases and from cerebrospinal fluid in one. Thirdly, the course of the illness is rapid and fulminant; no child survived 24 hours after acute collapse, and in three cases death followed less than 12 hours after the first symptoms. Finally, adrenal haemorrhage was found in four of the five cases.

\section{THERAPEUTIC AND PROPHYLACTIC CONSIDERATIONS}

Death of infection in a congenitally asplenic child is quick, and if it is to be prevented infection must be anticipated. This series focuses attention on the need for a comprehensive pro- gramme of screening with preventative and therapeutic measures to reduce the mortality. As the incidence of isolated congenital asplenia is low, screening should be limited to those children presenting with complex heart disease, particularly with atrial isomerism, and those with viscera sited abnormally in whom an ultrasound scan to assess splenic size and a blood film for Howell-Jolly bodies should be done. ${ }^{16}$ An abnormality of either would be an indication for a ${ }^{99 m} \mathrm{Tc}$ sulphur colloid scan. ${ }^{17}$ The use of dodecavalent pneumococcal vaccine in the older patients who have had their spleens removed is well established and reduces the risk from pneumococcal infection, although its role in congenitally asplenic children is less certain. ${ }^{18}$ In addition vaccination against $H$ influenzae is now available and should be considered for younger asplenic children.

Antibiotic prophylaxis, traditionally with penicillin for older children without spleens, ${ }^{8} 13$ should be with amoxycillin to offer protection against Haemophilus spp. ${ }^{8}$ When amoxycillin resistance in Haemophilus spp is common or in cases of penicillin sensitivity, trimethoprim may be substituted. Perhaps the most important benefit of detection by screening would be the opportunity to institute early treatment with parenteral antibiotics in cases of suspected sepsis, with steroid supplements to avoid endotoxic and adrenal collapse.

1 Ivemark BI. Implications of agenesis of the spleen on the pathogenesis of conotruncus anomalies in childhood. Acta Paediatrica 1955;44(Suppl 104): 1-110.

2 Gilbert EF, Nishimura K, Wedum G. Congenital malformation of the heart associated with splenic agenesis. Circulation 1958:17:72-83.

3 Freedom RM. The asplenia syndrome. A review of significant extracardiac structural abnormalities in 29 necropsied cant extracardiac structural abnorma

patients. F Pediatr 1972;18:1130-3.
4 Van Mierop LHS, Gessner IH, Schiebler GL. Asplenia and polysplenia syndrome. In: Bergsma D, ed. Congenital polysplenia syndrome. In: Bergsma D, ed. Congenital cardiac defects-recent advances. Birth defects:
article series. Baltimore: A R Liss 1982:36-44.

article series. Baltimore: A R Liss 1982:36-44.
5 Rose V, Izukawa T, Moes CAF. Syndromes of asplenia and polysplenia. A review of cardiac and non-cardiac malformations in 60 cases with special reference to diagnosis and prognosis. Br Heart 7 1975;37:840-52.

6 Ruttenberg HD, Neufeld HN, Lucas RV, et al. Syndrome of congenital cardiac disease with asplenia. Am $\mathcal{J}$ Cardiol 1964;13:387-406.

7 Marceletti C, Di Donato R, Nijveld A, et al. Right and left isomerism: the cardiac surgeon's view. Ann Thorac Surg 1983;35:400-5

8 Waldman JD, Rosenthal A, Smith AL, Shurin S, Nadas AS. Sepsis and congenital asplenia. $\mathcal{F}$ Pediatr 1977;90:555-9.

9 Di Donato R, di Carlo D, Squitieri C, et al. Palliation of cardiac malformations associated with right isomerism (asplenia syndrome) in infancy. Ann Thorac Surg 1987;44: 35-39.

10 Kevy SV, Tefft M, Vawter GF, Rosen FS. Hereditary splenic hypoplasia. Pediatrics 1968;42:752-7.

11 Dickerman JD. Bacterial infection in the asplenic host: a review. $\mathcal{F}$ Trauma 1976;16:662-7.

12 King K, Schumacher HB. Spenic studies I. Susceptibility to infection after splenectomy performed in infancy. Ann Surg 1952;136:239-42.

13 Lucas RV, Krivit W. Overwhelming infection in children following splenectomy. $\mathcal{F}$ Pediatr 1960;57:185-91

14 Gopal V, Bisno AL. Fulminant pneumococcal infections in 'normal' asplenic hosts. Arch Intern Med 1976;137:1526-30

15 Singer DB. Postsplenectomy sepsis. In: Rosenberg HS, Bolande RP, eds. Perspectives in pediatric pathology. Vol 1. Chicago: Year Book Medical Publishers, 1973:285-311.

16 Padmanabhan J, Risenberg HM, Rowe R. Howell-Jolly bodies in the peripheral blood of full term and premature bodies in the peripheral blood of full term and premature

17 Treves S, Spencer RP. Liver and spleen scintigraphy. Semin Nucl Med 1973;3:55-8.

18 Biggar WD, Ramirez RA, Rose V. Congenital asplenia: immunological assessment and a clinical review of eight surviving patients. Pediatrics 1981;67:548-51. 